\title{
Environmental and biological monitoring for the identification of main exposure determinants in vineyard mancozeb applicators
}

\section{Running title: Determinants of farmers' exposure to mancozeb}

\section{Stefan Mandic-Rajcevic, M.D., Ph.D.}

Department of Health Sciences of the University of Milan and International Centre for Rural Health of the San Paolo Hospital, Via San Vigilio 43, 20142 Milan, Italy

Federico Maria Rubino, Ph.D.

Department of Health Sciences of the University of Milan and International Centre for Rural Health of the San Paolo Hospital, Via San Vigilio 43, 20142 Milan, Italy

\section{Eugenio Ariano, M.D.}

Working Group for Prevention in Agriculture of the Region of Lombardy, Milan, Italy

Danilo Cottica, Ph.D.

Centre for Environmental Research, Fondazione Salvatore Maugeri, Pavia, Italy

Sara Neri, Ph.D.

Centre for Environmental Research, Fondazione Salvatore Maugeri, Pavia, Italy

\section{Claudio Colosio, M.D., Ph.D. *}

Department of Health Sciences of the University of Milan and International Centre for Rural Health of the San Paolo Hospital, Via San Vigilio 43, 20142 Milan, Italy

\section{* Corresponding Author}

Professor Claudio Colosio, M.D., Ph.D.

Department of Health Sciences of the University of Milan and International Centre for Rural Health of the San Paolo Hospital Via San Vigilio 43

20142 Milan

Italy

Phone: +39 0281843465

Mobile: +39 3401122183

Email: claudio.colosio@unimi.it 


\title{
Environmental and biological monitoring for the identification of main exposure determinants in vineyard mancozeb applicators
}

\section{Running title: Determinants of farmers' exposure to mancozeb}

\begin{abstract}
Grapevine is a vulnerable crop to several fungal diseases often requiring the use of ethylenebisdithiocarbamate (EBDC) fungicides, such as mancozeb. This fungicide has been reported to have goitrogenic, endocrine disrupting, and possibly immunotoxic effects. The aim of this study was to assess workers' exposure in two scenarios of mancozeb application and analyze the main determinants of exposure in order to better understand their mechanism of influence. Environmental monitoring was performed using a modified Organisation for Economic Co-operation and Development (OECD) “patch” methodology and by hand-wash collection, while mancozeb’s metabolite, ethylenethiourea (ETU), was measured in 24-hour pre- and post-exposure urine samples. Liquid chromatography-mass spectrometry was used for determination of mancozeb and ETU in different kinds of samples. Closed tractor use resulted in 40 times lower potential exposure compared to open tractor. Coveralls reduced skin exposure 4 and 10 times in case of open and closed tractors, respectively. Gloves used during application resulted in 10 times lower hand exposure in open, but increased exposure in closed tractors. This study has demonstrated that exposure to mancozeb is low if safe occupational hygiene procedures are adopted. ETU is confirmed as suitable biological marker of occupational exposure to mancozeb, but the absence of biological exposure limits significantly reduces the possibility to interpret biological monitoring results in occupationally exposed workers.
\end{abstract}

Key words: Coverals, Ethylene-bis-dithiocarbamates, Exposure assessment, farm workers, PPDs, 


\section{Introduction}

Cultivation of vines and winemaking is an important agricultural activity in the World, as well as in Italy. Grapevine is a crop vulnerable to several fungal diseases in different phases of its growth. Considering the importance of winemaking as an economic activity, protection of crops becomes a priority for big and small enterprises, and the use of fungicides is a necessity. Ethylene-bis-dithiocarbamate (EBDC) fungicides have been used to fight moulds in fruits for decades, due to their good fungicidal activity against many frequent plant pathogens such as downy mildew (Plasmopara viticola), powdery mildew (Uncinula necator), phomopsis (Phomopsis viticola), and black rot (Guingardia bidwelli).

The use of EBDC fungicides containing manganese and zinc, such as mancozeb, has been growing since their introduction in the market. As a general rule, all EBDCs are characterised by low acute toxicity and short environmental persistence (1). Nevertheless, the most used compound of this group, mancozeb, has been reported as having goitrogenic $(2,3)$ and endocrine disrupting effects (4-6), as well as being possibly immunotoxic (7-9). In mammals, mancozeb produces several metabolic products among which the most relevant is Ethylenebis-thiourea (ETU), which is also a product of its environmental degradation (10).

Published data suggest that ETU can be measured in workers occupationally exposed to EBDCs (11, 12). However, apart from the Acceptable Operator Exposure Level for mancozeb, stabilised in the authorization process $(13,14)$, there is no occupational exposure limit for ETU recommended by any official agency, rendering difficult the interpretation of the results of environmental and biological monitoring of exposure. Several studies investigated the use of ETU as a biomarker of occupational exposure $(7,11)$, and a reference value of $1 \mathrm{mcg} / \mathrm{g}$ creatinine was tentatively proposed for the unexposed population of Northern Italy (15). Therefore, even in the absence of officially validated occupational 
exposure limits, ETU can be used as a valid biological indicator of exposure in biological monitoring of EBDC exposed workers, but further studies could increase the possibilities for its use.

In agricultural application of pesticides, exposure can occur during mixing and loading (MIX) of the formulation, application (APPL), and maintenance and cleaning (MTNT) of the equipment $(16,17)$. Levels of exposure differ greatly between workers, depending on various determinants of exposure (16, 18-20). Performing field studies of occupational pesticide exposure in agriculture provides us with exposure measurements in real-life conditions of pesticide use. The results of field studies help us identify the main determinants of exposure, analyse their relationship, and produce information necessary for preventive interventions (16, 18).

The aim of this study was to assess and compare workers' exposure in two most common scenarios of mancozeb application in Italian vineyards, to define the main determinants of exposure in these scenarios, and to analyze their weight in determining the levels of exposure of the workers under study.

\section{Materials and Methods}

This study was carried out between April and July 2011 in Mantova and Pavia provinces of the Region of Lombardy (Northern Italy). Enterprises using EBDT fungicides, namely mancozeb, were selected, methods and aims of the study were described to employers and employees in dedicated meetings, and all participants signed the informed consent form approved by the Ethical Committee of our University Hospital.

The study protocol defined three levels of data collection: 
1) Original data collection sheet consisting of questions regarding the characteristics of the farmer, the farm, and the work day;

2) Assessment of potential (on clothes) and actual skin exposure using the "patch" methodology and collecting hand-wash liquid;

3) Assessment of excretion of the mancozeb metabolite, ETU, measured in 24-hour preexposure and 24-hour post-exposure urine samples.

A brief overview of the study concept is shown in Figure 1.

\subsection{Data collection sheet}

An original Data Collection Sheet was developed by our team to collect personal information of each participating worker, as well as all the information necessary to accurately describe the work day. It was based on a detailed analysis of published studies on pesticide exposure in agriculture. The Data Collection Sheet was in the Italian language, and an English version is reported as Supplementary material $\mathbf{S 1}$ in a published article (21).

\subsection{Assessment of potential and actual skin exposure}

Skin exposure of the body (hands excluded) was assessed according to the modified Organization for Economic Co-operation and Development (OECD) guidelines (22), using rectangular $0.01 \mathrm{~m}^{2}$ pads made of Whatman filter paper grade 1 (Prodotti Gianni, Milan). Four pads were placed on the clothes used during the work day, and 6 pads under the clothes on the skin. Pads on the clothes estimate the potential skin exposure (clothes contamination) defined as the amount of applied active ingredient which reaches the subjects' clothes; those on the skin estimate the actual skin exposure, defined as the amount of active ingredient reaching the skin, and available for absorption. The percentages of body surface represented by each pad were calculated using the Mosteller formula (23). 
Skin exposure of the hands was assessed by collecting the hand-wash liquid. Workers were asked to notify the study team each time they would usually wash their hands during the work-day, and they were asked to wash their hands with $200 \mathrm{~mL}$ of an aqueous solution of iso-propanol.

Respiratory route of exposure was not taken into consideration since it does not provide a significant contribution to the overall exposure in an outdoor application, being in the order of $0,1-7 \%$ of the total (24-26). Also, the burden on the workers was significantly reduced with this decision, with an increase of their compliance to the study protocol.

\subsection{Assessment of ETU excretion}

The evaluation of the excretion of mancozeb’s main metabolite, Ethylene-bis-thiourea (ETU), was done by collecting 24-hour urine samples in hospital urine containers. One 24-hour preexposure (starting on the morning of the day before the application, and ending before work of the morning of the application) and a 24-hour post-exposure urine sample (starting at the end of the application and collecting for 24 hours) were collected from each worker. All urine containers were stored closed at $+4^{\circ} \mathrm{C}$ until conveyed to the laboratory.

\subsection{Sample preparation and analysis}

The determination of mancozeb and ETU in different samples (pads, hand wash and urine) was done by liquid chromatography-mass spectrometry. Specifically, with Acquity UPLC system (Waters, Milford, MA, USA) coupled with a triple quadrupole Waters TQD mass spectrometer. TQD detector with an ESI interface in positive ion mode (ESI+) was used for quantitative analysis. The MRM acquisition used to quantify ETU was: m/z $103 \rightarrow 44$ (CV 36, CE 16); for internal standard ETU D4 quantification was obtained in SIR: m/z 107 (CV35). UPLC separation was performed on a Waters UPLC HSS T3 $1.8 \mu \mathrm{m}(2.1 \mathrm{x} 100 \mathrm{~mm})$ column kept at $28^{\circ} \mathrm{C}$, by gradient elution with a mixture containing variable proportion of 
water and methanol, delivered at a flow rate of $0.4 \mathrm{ml} / \mathrm{min}$. The retention time of ETU and its internal standard was $1.3 \mathrm{~min}$.

Details regarding the analytical methods adopted for the study are shown in Table 1.

\subsection{Exposure assessment, data processing and statistical analysis}

From concentrations of mancozeb $(\mathrm{mg} / \mathrm{L}$ or $\mathrm{mcg} / \mathrm{L})$ in individual samples, the absolute amount in the original sample was calculated in micrograms. The potential skin exposure of the body was calculated as the sum of regional exposures which were measured by external pads (on the clothes), taking into account the surface of the pad and the body region represented by each pad, according to the formula:

$$
\begin{aligned}
& \text { Potential sktn exposure bedy }(\mathrm{mg}) \\
& =\sum_{p a d=1}^{4} \operatorname{Mancozeb}_{p a d}\left(m g / d m^{2}\right) \times \text { Body area represented }{ }_{p a d}\left(\mathrm{dm}^{2}\right)
\end{aligned}
$$

The actual skin exposure of the body was calculated as the sum of regional exposures calculated from the amount of mancozeb measured in the skin pads multiplied by the surface of each region represented by the pads:

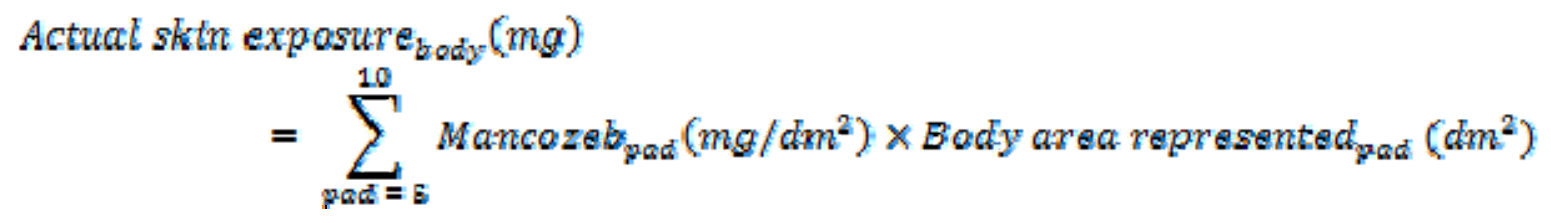

Protection factor is the fraction of pesticide retained by the barrier of the work clothing layer (27), and was calculated as:

Protection Factor $=\frac{\text { Potential sktn exposure }}{\text { Potential sktn exposure }+ \text { Actual sktn exposure }}$ expressed in percentages. 
Data processing and statistical analyses were performed in $\boldsymbol{R}$ language and Environment for Statistical Computing (28). Median, minimum, and maximum values are reported in Tables, and non-parametric statistical tests, such as Mann-Whitney and Kruskal-Wallis tests were used to compare differences between groups, based on the Shapiro-Wilk test for normality of each variable of interest. In order to estimate correlation coefficients, data were first log transformed, and if normality was achieved, Pearson correlation was tested.

\section{Results}

\subsection{Workers, work-day characteristics and personal protective devices}

A total number of 29 healthy, right-handed, male workers participated in this study (Figure 1). The main relevant characteristics of the subjects are shown in Table 2. The workers were followed by a 3-person field team during their normal working activities, which included the preparation of the spray solution and filling the tank of the tractor-mounted sprayer (MIX), spraying the pesticide (APPL), and routine after-work maintenance and cleaning of the equipment (MNTN).

The workers used closed and filtered tractors (CFT) in 29 work days, while open tractors (OT) were used in 9 work days. The main characteristics of work days are presented in Table

3. The median tank capacity for OT was 300 litres, while for CFT it was 1000 litres. MIX was done 2 times per day, but on some occasions up to 7 times during one work day. Most workers used mancozeb in a soluble granule formulation. The median covered area per work day was 6 hectares, but ranged from 1 to 20 ha. Up to 50\% of the workers cleaned their equipment after work, and almost $80 \%$ of the workers washed the tank. Workers reported MNTN was done routinely in $84 \%$ of the cases (up to almost $90 \%$ in CFT).

Personal protective devices (PPDs) availability, characteristics, and use are reported in Tables 4 and 5. Most workers were equipped with new mono-use coverals, and most used normal 
clothes below the coverals. Gloves were available in all cases when workers used OTs, and in most cases (96.6\%) when CFTs were used. Gloves were made of rubber in most cases (63\%), followed by neoprene (29\%) and latex.

Almost all workers used gloves during MIX and MNTN phases, but 78\% and 21\% used them during the APPL in OT and CFT, respectively. This difference was statistically significant ( $\mathrm{p}$ $=0.003)$. Most workers used masks with various types of filters during MIX phase (84\%), and most did not use it during the MNTN phase (70\%). During the APPL phase 88\% of OT workers and only $24 \%$ of CFT workers used respiratory protection, and this difference was statistically significant $(\mathrm{p}=0.002)$.

\subsection{Exposure assessment and biological monitoring}

Results of environmental and biological monitoring are presented in Table 6. The median potential exposure of workers using OTs was just above $6 \mathrm{mg}$, ranging from $53 \mathrm{mcg}$ to more than $20 \mathrm{mg}$, and was significantly lower for workers using CFTs, with a median of $159 \mathrm{mcg}$, ranging from 15 to $7658 \mathrm{mcg}$. The median contamination on clothes was $1.2 \mathrm{mcg} / \mathrm{cm}^{2}$, and differed significantly between OT $\left(24.88 \mathrm{mcg} / \mathrm{cm}^{2}\right)$ and CFT $\left(0.90 \mathrm{mcg} / \mathrm{cm}^{2}\right)$. The difference in potential exposure between two groups of workers was statistically significant $(p=0.005$ and $p=0.006$ respectively). Gloves were exposed at a median level of 12.78 mcg. Median skin exposure was $1.62 \mathrm{mcg}$, just below 4 mcg for workers using OTs, and 1.45 mcg for those

using CFTs. Median skin contamination was $0.009 \mathrm{mcg} / \mathrm{cm}^{2}$. Median hand exposure was 232 mcg for OTs, and 77 mcg for CFTs. Total potential exposure (contamination on clothes and gloves) was 305 mcg, while the total actual exposure (skin and hands) was 147 mcg. The difference between OTs and CFTs was statistically significant for total potential exposure (p $=0.008)$, but was not for total actual exposure $(\mathrm{p}=0.187)$. 
The median pre-exposure urine levels of ETU were 1.04 and 0.86 mcg (or 0.93 and 0.51 mcg/g of creatinine) for OT and CFT workers respectively. The median post-exposure urine levels of ETU were 3.02 and $2.51 \mathrm{mcg}$ (or 3.02 and $2.06 \mathrm{mcg} / \mathrm{g}$ of creatinine) for open and closed and filtered tractor workers respectively.

\subsection{Determinants of exposure}

Mono-use coveral provide the highest body protection, followed by the multi-use coveral and regular clothes. Mono- and multi-use coverals were able to block almost $99 \%$ of potential exposure, while normal clothes prevented only around 65\% of potential exposure from reaching the skin (Figure 2).

Figure 3 demonstrates the relative contribution of hands and body exposure to the total skin exposure in each worker. In all but three cases hand exposure contributed more than $90 \%$ of the total skin exposure, and in many cases more than 99\%. In the mixing and loading phase most workers in our study used gloves (see Table 5), therefore we explored the importance of the use of gloves in the application phase. Figure 4 demonstrates the influence of gloves on hands' exposure in OT and CFT. When OTs were used, the use of gloves reduced the exposure of hands from 5 to 10 times, while when CFTs were used there was no reduction, but an increase of exposure. Figure 4 also confirms the importance of the tractor type on the overall exposure, considering the contribution of hands exposure to total skin exposure.

\subsection{ETU as a biomarker of occupational exposure to mancozeb}

Figure 5 demonstrates the pre- and post-exposure ETU levels in each worker individually (each worker is represented with the two levels connected with a straight line). The color denotes whether there was an increase of the ETU level (red). For most workers we can see an increase in the post-exposure urine ETU level, regardless of the type of tractor used, although there is a number of subjects, denoted by green color, in whom the urine ETU levels 
decreased. Post-exposure ETU level was significantly higher than the pre-exposure level (Wilcoxon signed rank test: $V=99, \mathrm{p}<0.001$ ). Since both the total skin exposure and the post-exposure ETU urine levels were not normally distributed, they were logarithmically transformed and checked again for normality (data not shown). A Pearson product-moment correlation coefficient was computed to assess the relationship between the total skin exposure and the post-exposure ETU urine levels. There was a statistically significant positive correlation between the total skin exposure and ETU levels $(r=0.55, t=3.78, p<0.001)$. When correlation was tested only for subjects whose levels of ETU increased after application, indicating the influence of occupational exposure and not environmental exposure, there was an even stronger significant positive correlation $(r=0.67, t=4.35, p<$ $0.001)$.

\section{Discussion and Conclusions}

This article presents a detailed exposure analysis of mancozeb applicators in vineyards, which included environmental monitoring, biological monitoring, and a detailed data collection to describe real-life field conditions of pesticides use in vineyards (see Figure 1). The study was conducted on a relatively large sample of applicators (29 subjects, 38 work days), considering that most similar studies include between 7 and 15 work days. Two most common methods of application, namely open (OT) and closed and filtered tractors (CFT) were analysed, with 9 and 29 monitoring days respectively. These characteristics allowed for a better generalisation of the results compared to other studies, where only a small number of workers performed application using the same method $(21,29-31)$.

All study subjects were male, which was expected considering the standards in the agricultural sector and pesticide application (21, 30, 31). Their height was average, but their weight, with a median of $80 \mathrm{~kg}$, was somewhat higher than average (see Table 2), especially 
considering default values of models used in the authorization process $(21,32,33)$. Closed and filtered tractors were mostly used on a terrain which is not excessively steep, covering a larger area and spraying more product, which was, in this study (see Table 3), shown by a higher tank capacity, larger treated area and longer application times. Other characteristics of the work, such as the number of different operations, the physical form of the product used, and the performance of maintenance and cleaning of equipment did not depend on the tractor type and were not significantly different between the two types of tractor considered. Factors such as the windiness or temperature, although recorded by the Data Collection Sheet, were not variable, as the workers applied mancozeb in the same region, always choosing days with little or no wind and similar mild weather conditions.

The majority of the workers had mono-use coverals available, which is known to provide best protection during the monitoring work days (see Table 4). In this study, the use of mono-use coverals as opposed to multi-use coverals resulted in 4 times lower skin exposure when OT was used, and using any of the two resulted in 10 times lower skin exposure in the case of CFT when compared to normal clothes. Mono- and multi-use coverals blocked 99\% of exposure on clothes from reaching the skin (see Figure 2), which confirms our results with tebuconazole (21), albeit higher than that estimated in similar studies (24, 29, 34-36). Nevertheless, the different modalities of application explored by other authors must be considered.

Most workers had at least gloves and a mask available for personal protection, aside from the coveral (see Table 4). As for PPDs used in different phases of the work, most workers used gloves and respiratory protection during mixing and loading, and gloves during maintenance. The biggest difference was observed in the application phase, where most (77\%) open tractor, and 6 (20\%) closed and filtered tractor workers used gloves (see Table 5). The use of gloves during application resulted in 10 times lower median hand exposure in OT workers, but 3 
times higher median hand exposure in CFT workers (see Figure 4). The use of gloves in a closed and filtered tractor is considered a wrong practice, since contaminated gloves are brought into a clean environment and can result in surface contamination, leading to higher exposure (37-39). Our results have demonstrated this higher exposure.

Both groups of workers, using open as well as closed and filtered tractors, were exposed to only few micrograms of the active substance, although we have seen a high variability (see Table 6), which is consistent with published literature (21, 31). We can attribute the relatively low exposure to the modality of application, as the use of open as well as closed tractors is considered to result in the lowest exposure $(16,18)$. Potential (clothes and gloves) and actual (skin and hands) exposure was consistently several times lower when CFTs were used. Figure 6 shows a comparison of potential (clothes and glove) and actual (skin and hands) exposure levels between OT and CFT. The protection offered by the tractor cabin in case of CFT has been studied and consistently demonstrated (21, 30, 40). Likewise, in our study the use of CFT resulted in 40 times lower median potential exposure, almost 3 times lower median glove and skin exposure, and more than 3 times lower median hands exposure, compared to OT.

The high contribution of hands' exposure to the total exposure (see Figure 3) has been demonstrated in previous studies $(21,41)$. The question that can be raised, since most of the workers washed their hands several times during the day, is whether it was correct to treat the handwash liquid as hand exposure. As the hands get contaminated, the worker was exposed via hands only before they were washed. This would mean that one handwash sample does not measure exposure during the whole day, but only in the period (several hours) before it is collected. Therefore, the duration of hand exposure should be considered for each handwash sample to gain more precise results $(42,43)$. To our knowledge, this has never been applied previously in pesticide exposure and risk studies, and should be a subject of future studies. 
Finally, this study confirms that ETU is a suitable biomarker for monitoring occupational exposure to mancozeb in agricultural pesticide applicators. Post-exposure ETU urine levels were significantly higher than pre-exposure levels, indicating that an increase of ETU in urine can be measured even if the workers are not highly exposed to mancozeb, as in our study (see Section 3.5.). The suitability is also confirmed by the statistically significant positive correlation between the total skin exposure and post-exposure ETU level in our workers $(\mathrm{r}=$ 0.55 and $r=0.67)$, which confirms findings of a previous similar study (11). Unfortunately, the lack of biological occupational exposure limits significantly reduces the possibility to use this biomarker in routine risk assessment activities. Nevertheless, studies including both environmental and biological monitoring, such as this one, allow ETU to be used in computational modelling which could result in a biological limit of exposure (40).

One of the main principles of this study was to analyze the real-life conditions of exposure to mancozeb in agricultural application, which resulted in several limitations. Our methods included exposure monitoring using a modified OECD protocol with a reduced number of pads, which can lead to a lower precision in the estimate of exposure, but has allowed us not to disturb the workers excessively. The percentage of workers using mono-use coverals appears unrealistically high, and can be explained by the worker’s effort to appear better equipped for our study. Our team has underlined the interest to see “real-life condition” in which the workers perform their job, but it was impossible not to influence the workers' choice in this case. Only nine open tractor work days might have led to some results not reaching statistical significance (compared to 29 closed and filtered tractor work days), especially in the exposure assessment, but our study has shown without any doubt that exposure (potential and actual) is consistently lower when CFTs are used. Considering similar application scenarios in the South of Italy or any Mediterranean country, we would expect workers not to use PPDs throughout the day due to the increased temperature and fewer 
controls by the labor inspection. Therefore, the exposure could be in the order of magnitude of workers wearing only normal clothes and no gloves in our study. Nevertheless, a study with a higher number of participants and workdays would be necessary to confirm our results, and make the above conclusions more generalizable.

In conclusion, this study has demonstrated that the levels of exposure to mancozeb in Italian vineyards are extremely low if workers adopt safe occupational hygiene procedures. The major part of exposure came from hands' contamination, which contributed with more than $90 \%$ to the total skin exposure, although the duration of exposure should be considered in risk assessment efforts. Principal determinants of exposure to mancozeb were the type of tractor (OT vs CFT), and PPDs used, namely the coveral and the gloves. The adoption of unsafe practice, such as bringing contaminated gloves into a closed and filtered tractor, resulted in significantly higher levels of hand exposure. Finally, our study confirmed that ETU is a suitable biological marker of occupational exposure to mancozeb, but the absence of biological exposure limits greatly reduces the possibility to interpret biological monitoring results in occupationally exposed workers. However, the high correlation between ETU levels and total skin exposure opens the door to developing methods for better interpretation using the integration of biological monitoring, environmental monitoring, and computer modelling. This topic deserves further studies.

\section{Acknowledgments}

We acknowledge the support of the Italian Institute for Insurance of Occupational Diseases and Accidents (INAIL) - Session of the Region of Lombardy, which funded this study.

\section{Conflict of Interest}

The authors declare NO competing financial interest in relation to the work described. 


\section{References}

1. Maroni M, Colosio C, Ferioli A, Fait A. Biological Monitoring of Pesticide Exposure: a review. Introduction. Toxicology. 2000;143(1):1-118.

2. Vergova M, Jablonica A, Janota S. Occupational exposure to mancozeb in employees in the production of Novozir Mn 80. Pracovni Lekarstvi. 1988;40:425-30.

3. Smith DM. Ethylene thiourea: thyroid function in two groups of exposed workers. British journal of industrial medicine. 1984;41(3):362-6.

4. Cecconi S, Paro R, Rossi G, Macchiarelli G. The effects of the endocrine disruptors dithiocarbamates on the mammalian ovary with particular regard to mancozeb. Current pharmaceutical design. 2007;13(29):2989-3004.

5. Bisson M, Hontela A. Cytotoxic and endocrine-disrupting potential of atrazine, diazinon, endosulfan, and mancozeb in adrenocortical steroidogenic cells of rainbow trout exposed in vitro. Toxicology and Applied Pharmacology. 2002;180(2):110-7.

6. Panganiban L, Cortes-Maramba N, Dioquino C, Suplido ML, Ho H, Francisco-Rivera A, et al. Correlation between blood ethylenethiourea and thyroid gland disorders among banana plantation workers in the Philippines. Environmental health perspectives. 2004;112(1):42.

7. Colosio C, Fustinoni S, Corsini E, Bosetti C, Birindelli S, Boers D, et al. Changes in serum markers indicative of health effects in vineyard workers following exposure to the fungicide mancozeb: an Italian study. Biomarkers. 2007;12(6):574-88.

8. Corsini E, Viviani B, Birindelli S, Gilardi F, Torri A, Codecà I, et al. Molecular mechanisms underlying mancozeb-induced inhibition of TNF-alpha production. Toxicology and applied pharmacology. 2006;212(2):89-98.

9. Corsini E, Liesivuori J, Vergieva T, Van Loveren H, Colosio C. Effects of pesticide exposure on the human immune system. Human \& experimental toxicology. 2008;27(9):67180.

10. Somerville L. The metabolism of fungicides. Xenobiotica. 1986;16(10-11):1017-30. 11. Colosio C, Fustinoni S, Birindelli S, Bonomi I, De Paschale G, Mammone T, et al. Ethylenethiourea in urine as an indicator of exposure to mancozeb in vineyard workers. Toxicology Letters. 2002;134(1-3):133-40.

12. Kurttio P, Vartiainen T, Savolainen K. Environmental and biological monitoring of exposure to ethylenebisdithiocarbamate fungicides and ethylenethiourea. British journal of industrial medicine. 1990;47(3):203-6. 
13. EU Regulation. No 1107/2009 of the European Parliament and of the Council of 21 October 2009 concerning the placing of plant protection products on the market and repealing Council Directives 79/117/EEC and 91/414/EEC. EU, Brussels. 2009.

14. EU SANCO. Review report for the active substance mancozeb. European Comission Health \& Consumer Protection Directorate-General, 2009.

15. Colosio C, Visentin S, Birindelli S, Campo L, Fustinoni S, Mariani F, et al. Reference values for ethylenethiourea in urine in Northern Italy: results of a pilot study. Toxicology Letters. 2006;162(2-3):153-7.

16. Arbuckle TE, Burnett R, Cole D, Teschke K, Dosemeci M, Bancej C, et al. Predictors of herbicide exposure in farm applicators. International Archives of Occupational and Environmental Health. 2002;75(6):406-14.

17. Damalas CA, Koutroubas SD. Farmers' exposure to pesticides: toxicity types and ways of prevention. Toxics 4:1-10.

18. Coble J, Arbuckle T, Lee W, Alavanja M, Dosemeci M. The validation of a pesticide exposure algorithm using biological monitoring results. Journal of Occupational and Environmental Hygiene. 2005;2(3):194-201.

19. Brouwer DH, Marquart H, van Hemmen JJ. Proposal for an approach with default values for the protection offered by PPE, under European new or existing substance regulations. The Annals of Occupational Hygiene. 2001;45(7):543-53.

20. Gomes J, Lloyd OL, Revitt DM. The influence of personal protection, environmental hygiene and exposure to pesticides on the health of immigrant farm workers in a desert country. International Archives of Occupational and Environmental Health. 1999;72(1):40-5. 21. Mandic-Rajcevic S, Rubino FM, Vianello G, Fugnoli L, Polledri E, Mercadante R, et al. Dermal exposure and risk assessment of tebuconazole applicators in vineyards. La Medicina Del Lavoro. 2015;106(4):294-315.

22. OECD. Guidance Document for the Conduct of Studies of Occupational Exposure to Pesticides During Agricultural Application. 1997.

23. Mosteller RD. Simplified calculation of body-surface area. The New England Journal of Medicine. 1987;317(17):1098.

24. Vitali M, Protano C, Del Monte A, Ensabella F, Guidotti M. Operative modalities and exposure to pesticides during open field treatments among a group of agricultural subcontractors. Archives of Environmental Contamination and Toxicology. 2009;57(1):193202. 
25. Aprea C, Terenzoni B, De Angelis V, Sciarra G, Lunghini L, Borzacchi G, et al. Evaluation of skin and respiratory doses and urinary excretion of alkylphosphates in workers exposed to dimethoate during treatment of olive trees. Archives of Environmental Contamination and Toxicology. 2005;48(1):127-34.

26. Flack S, Goktepe I, Ball LM, Nylander-French LA. Development and application of quantitative methods for monitoring dermal and inhalation exposure to propiconazole. Journal of Environmental Monitoring. 2008;10(3):336-44.

27. Lima CS, Nunes-Freitas AL, Ribeiro-Carvalho A, Filgueiras CC, Manhaes AC, Meyer A, et al. Exposure to methamidophos at adulthood adversely affects serotonergic biomarkers in the mouse brain. Neurotoxicology. 2011;32(6):718-24.

28. R Core Team. R: A language and environment for statistical computing. R Foundation for Statistical Computing, Vienna, Austria. 2012.

29. Aprea MC. Environmental and biological monitoring in the estimation of absorbed doses of pesticides. Toxicology Letters. 2012;210(2):110-8.

30. Rubino FM, Mandic-Rajcevic S, Ariano E, Alegakis A, Bogni M, Brambilla G, et al. Farmers' exposure to herbicides in North Italy: Assessment under real-life conditions in small-size rice and corn farms. Toxicology Letters. 2012;210(2):189-97.

31. Tsakirakis AN, Kasiotis KM, Charistou AN, Arapaki N, Tsatsakis A, Tsakalof A, et al. Dermal \& inhalation exposure of operators during fungicide application in vineyards. Evaluation of coverall performance. Science of the Total Environment. 2014;470-471:282-9. 32. Lundehn J, Westphal D, Kieczka H. Uniform principles for safeguarding the health of applicators of plant protection products. Mitteilungen aus der Biologischen Bundesanstalt für Land- und Forstwirtschaft. 1992;227:60-112.

33. van Hemmen JJ. EUROPOEM, a predictive occupational exposure database for registration purposes of pesticides. Applied occupational and environmental hygiene. 2001;16(2):246-50.

34. Fenske RA, Blacker AM, Hamburger SJ, Simon GS. Worker exposure and protective clothing performance during manual seed treatment with lindane. Archives of Environmental Contamination and Toxicology. 1990;19(2):190-6.

35. Protano C, Guidotti M, Vitali M. Performance of different work clothing types for reducing skin exposure to pesticides during open field treatment. Bulletin of Environmental Contamination and Toxicology. 2009;83(1):115-9. 
36. Machera K, Tsakirakis A, Charistou A, Anastasiadou P, Glass CR. Dermal exposure of pesticide applicators as a measure of coverall performance under field conditions. Annals of Occupational Hygiene. 2009;53(6):573-84.

37. Hines CJ, Deddens JA, Tucker SP, Hornung RW. Distributions and determinants of pre-emergent herbicide exposures among custom applicators. Annals of Occupational Hygiene. 2001;45(3):227-39.

38. Yoshida K, Fuzesi I, Suzan M, Nagy L. Measurements of surface contamination of spray equipment with pesticides after various methods of application. Journal of Environmental Science and Health Part B-Pesticides Food Contaminants and Agricultural Wastes. 1990;25(2):169-83.

39. Sanderson WT, Ringenburg V, Biagini R. Exposure of commercial pesticide applicators to the herbicide alachlor. American Industrial Hygiene Association journal. 1995;56(9):890-7.

40. Colosio C, Rubino FM, Alegakis A, Ariano E, Brambilla G, Mandic-Rajcevic S, et al. Integration of biological monitoring, environmental monitoring and computational modelling into the interpretation of pesticide exposure data: introduction to a proposed approach. Toxicology Letters. 2012;213(1):49-56.

41. Baldi I, Lebailly P, Jean S, Rougetet L, Dulaurent S, Marquet P. Pesticide contamination of workers in vineyards in France. Journal of Exposure Science and Environmental Epidemiology. 2006;16(2):115-24.

42. Hoang K. Dermal exposure assessment: principles and applications. United States Environmental Protection Agency. 1992.

43. Frasch HF, Dotson GS, Bunge AL, Chen CP, Cherrie JW, Kasting GB, et al. Analysis of finite dose dermal absorption data: Implications for dermal exposure assessment. Journal of Exposure Science and Environmental Epidemiology. 2014;24(1):65-73. 


\section{Figure legends}

Figure 1. Concept of the study

Figure 2. Protection offered by normal clothes (None), multi- and mono-use coverals

Figure 3. Contribution of hands and body exposure to the total skin exposure in each worker.

Figure 4. Influence of gloves used during the application phase on hand exposure in OTs and CFTs

Figure 5. Pre- and post-exposure ETU levels in each worker

Figure 6. Comparison of potential and actual exposure levels between OT and CFT 


\section{Matrix}

Clothes

and Skin

pads

Hand wash Hand wash (200 mL iso-propanol solution) was rotavaporconcentrated and filtered before analysis.

Purification by solid-phase extraction on OASIS HLB (0.2 g, $5 \mathrm{~mL}$ ) SPE cartridges.

Urine Acid hydrolysis followed by liquid-liquid extraction with diethyl ether.

\section{Conditions}

HPLC system: Shimadzu Model LC -10AD pump and Shimadzu Model SPD-M10Avp UV-Vis diode array detector. Analytical column: Purospher C18e (250* 4 mm; $5 \mu \mathrm{m}$; Agilent Technologies) operated at $40^{\circ} \mathrm{C}$. Separation: gradient elution at $1 \mathrm{~mL} / \mathrm{min}$ of phosphate buffer $0.02 \mathrm{M}$, pH 6.8 and AcCN. Linear gradient of $0 \%$ to $30 \%$ buffer $/ 70 \%$ AcCN within 20 min. UV detection at $220 \mathrm{~nm}$.

HPLC-MS/MS system: Perkin Elmer-Sciex API 300 with Series 200

LC quaternary pump. Analytical column: Hypersil (15 x 4.6 mm, 5 $\mu \mathrm{m})$. Separation: gradient elution (mobile phase A: phosphate buffer:AcCN, 70:30, v/v; mobile phase B: phosphate buffer:AcCN, $80: 20, \mathrm{v} / \mathrm{v})$.

\section{HRGC-(EI)LRMS system:}

injection volume: $2 \mu \mathrm{l}$; injector temperature: $270^{\circ} \mathrm{C}$ (splitless) detector temperature: $280^{\circ} \mathrm{C}$; carrier gas: helium $\left(1 \mathrm{ml}^{*} \mathrm{~min}^{-1}\right)$ column: DB-5 $30 \mathrm{~m}$, i.d. $0.25 \mathrm{~mm}, 0.25 \mu \mathrm{m}$ oven temperature: $120^{\circ} \mathrm{C}(15 \mathrm{~min}) ; 20^{\circ} \mathrm{C} / \mathrm{min}$ to $240^{\circ} \mathrm{C}(2 \mathrm{~min})$

SIM: m/z 106, 141, 77 for the IS; m/z 161, 163, 99 for 3,4- and 3,5DCA:

\section{LoD and LoQ}

$\mathrm{LoD}=0.04 \mathrm{mg}^{*} \mathrm{~mL}^{-1}$ $\mathrm{LoQ}=0.12 \mu \mathrm{g} * \mathrm{~mL}^{-1}$. $\mathrm{LoQ}=0.12 \mu \mathrm{g} * \mathrm{~mL}^{1}$

LOD $0,005 \mu \mathrm{g} * \mathrm{~L}^{-1}$. $\mathrm{LoQ}=0.015 \mu \mathrm{g} * \mathrm{~mL}^{-1}$.

Table 1. Analytical methods for ETU employed for the analysis of field samples. 


\begin{tabular}{lcccc} 
& ALL & OT & CFT & \\
& $\mathrm{N}=29$ & $\mathrm{~N}=8$ & $\mathrm{~N}=21$ & $p$ \\
\hline Sex: Males (\%) & $29(100 \%)$ & $8(100 \%)$ & $21(100 \%)$ & $\cdot$ \\
Age (years) & $45(32-63)$ & $44(36-56)$ & $47(32-63)$ & 0.420 \\
Height (cm) & $177(162-190)$ & $176(172-184)$ & $177(162-190)$ & 0.448 \\
Weight (kg) & $85(62-120)$ & $90(75-120)$ & $82(62-100)$ & 0.339 \\
BSA $\left(\mathrm{cm}^{2}\right)$ & $205(167-248)$ & $212(191-248)$ & $202(167-230)$ & 0.283 \\
Experience (years) & $20(4-38)$ & $22(4-38)$ & $15(6-35)$ & 0.249
\end{tabular}

Table 2. Characteristics of the study population

${ }^{1}$ Data presented per worker, while in the following Tables data is presented per work day. 


\begin{tabular}{lcccc} 
& ALL & OT & CFT & \\
& $\mathrm{N}=38$ & $\mathrm{~N}=9$ & $\mathrm{~N}=29$ & $p$ \\
\hline Tank capacity (L) & $1000(200-2000)$ & $300(200-800)$ & $1000(300-2000)$ & $<0.001$ \\
No. of MIX & $2(1-7)$ & $2(1-7)$ & $2(1-6)$ & 0.669 \\
Duration MIX (min) & $15(10-60)$ & $10(10-40)$ & $20(10-60)$ & 0.121 \\
Product form ${ }^{1}$ : & & & & 0.131 \\
$\quad$ GN & $32(84 \%)$ & $6(67 \%)$ & $26(90 \%)$ & \\
PD & $6(16 \%)$ & $3(33 \%)$ & $3(10 \%)$ & \\
Area treated (ha) & $6(1-20)$ & $2(1-17)$ & $7(2-20)$ & 0.011 \\
Duration APPL (min) & $180(60-600)$ & $120(60-420)$ & $180(75-600)$ & 0.061 \\
Cleaning & $11(38 \%)$ & $3(43 \%)$ & $8(36 \%)$ & 1.000 \\
$\quad$ No & $18(62 \%)$ & $4(57 \%)$ & $14(64 \%)$ & \\
Yes & & & & 0.180 \\
Tank washed & $4(12 \%)$ & $2(29 \%)$ & $2(7 \%)$ & \\
No & $30(88 \%)$ & $5(71 \%)$ & $25(93 \%)$ & \\
$\quad$ Yes & $2(6 \%)$ & $1(14 \%)$ & $1(4 \%)$ & \\
Regular MNTN & $32(94 \%)$ & $6(86 \%)$ & $26(96 \%)$ & \\
No & &
\end{tabular}

Table 3. Work day characteristics

${ }^{1}$ Product form: granules (GN) or wettable powder (PD) 


\begin{tabular}{|c|c|c|c|c|}
\hline & $\begin{array}{c}\text { ALL } \\
\mathrm{N}=38\end{array}$ & $\begin{array}{c}\text { OT } \\
N=9\end{array}$ & $\begin{array}{c}\text { CFT } \\
N=29\end{array}$ & $p$ \\
\hline Coveral type & & & & 0.573 \\
\hline Mono-use & 28 (74\%) & 7 (78\%) & 21 (72\%) & \\
\hline Multy-use & $6(16 \%)$ & 2 (22\%) & $4(14 \%)$ & \\
\hline None & $4(11 \%)$ & $0(0 \%)$ & $4(14 \%)$ & \\
\hline Coveral state & & & & 0.053 \\
\hline New & 28 (82\%) & 7 (78\%) & 21 (84\%) & \\
\hline Clean & $4(12 \%)$ & $0(0 \%)$ & $4(16 \%)$ & \\
\hline Dirty & $2(6 \%)$ & 2 (22\%) & $0(0 \%)$ & \\
\hline Under coveral & & & & 0.432 \\
\hline Normal clothes & 35 (95\%) & 8 (89\%) & 27 (96\%) & \\
\hline Underwear & $2(5 \%)$ & 1 (11\%) & $1(4 \%)$ & \\
\hline Gloves available & & & & 1.000 \\
\hline No & $1(3 \%)$ & $0(0 \%)$ & $1(3 \%)$ & \\
\hline Yes & 37 (97\%) & $9(100 \%)$ & 28 (97\%) & \\
\hline Gloves material & & & & 0.054 \\
\hline Latex & $2(5 \%)$ & 2 (22\%) & $0(0 \%)$ & \\
\hline Neoprene & $11(30 \%)$ & $1(11 \%)$ & $10(36 \%)$ & \\
\hline Rubber & 24 (65\%) & $6(67 \%)$ & 18 (64\%) & \\
\hline Gloves state & & & & 1.000 \\
\hline New & 18 (50\%) & $4(50 \%)$ & $14(50 \%)$ & \\
\hline Used & 18 (50\%) & $4(50 \%)$ & $14(50 \%)$ & \\
\hline Feet protection & & & & 0.440 \\
\hline Regular shoes & $21(55 \%)$ & $4(44 \%)$ & 17 (59\%) & \\
\hline Boots & 9 (24\%) & 4 (44\%) & $5(17 \%)$ & \\
\hline Protective shoes & 8 (21\%) & 1 (11\%) & 7 (24\%) & \\
\hline Respiratory protection & & & & 0.417 \\
\hline No mask & $5(14 \%)$ & $1(11 \%)$ & 4 (14\%) & \\
\hline Paper mask (FFP1S) & $5(14 \%)$ & 1 (11\%) & $4(13 \%)$ & \\
\hline Filter mask (various) & 28 (74\%) & 7 (78\%) & $21(72 \%)$ & \\
\hline
\end{tabular}

Table 4. Personal protective devices availability and characteristics 


\begin{tabular}{lcccc} 
& ALL & OT & CFT & \\
& N=38 & N=9 & N=29 & $p$ \\
\hline Gloves MIX & & & & 1.000 \\
$\quad$ No & $1(3 \%)$ & $0(0 \%)$ & $1(3 \%)$ & \\
$\quad$ Yes & $37(97 \%)$ & $9(100 \%)$ & $28(97 \%)$ & \\
Gloves APPL & & & & 0.003 \\
$\quad$ No & $25(66 \%)$ & $2(22 \%)$ & $23(79 \%)$ & \\
$\quad$ Yes & $13(34 \%)$ & $7(78 \%)$ & $6(21 \%)$ & \\
Gloves MNTN & & & & 1.000 \\
$\quad$ No & $4(12 \%)$ & $1(12 \%)$ & $3(12 \%)$ & \\
$\quad$ Yes & $30(88 \%)$ & $7(88 \%)$ & $23(88 \%)$ & \\
Respiratory MIX & & & & 0.591 \\
$\quad$ No & $6(16 \%)$ & $2(25 \%)$ & $4(14 \%)$ & \\
$\quad$ Yes & $31(84 \%)$ & $6(75 \%)$ & $25(86 \%)$ & \\
Respiratory APPL & & & & 0.002 \\
$\quad$ No & $23(62 \%)$ & $1(12 \%)$ & $22(76 \%)$ & \\
$\quad$ Yes & $14(38 \%)$ & $7(88 \%)$ & $7(24 \%)$ & \\
Respiratory MNTN & & & & 1.000 \\
No & $23(70 \%)$ & $5(71 \%)$ & $18(69 \%)$ & \\
Yes & $10(30 \%)$ & $2(29 \%)$ & $8(31 \%)$ & \\
\hline
\end{tabular}

Table 5. Personal protective equipment used in different phases of work 


\begin{tabular}{|c|c|c|c|c|}
\hline & $\begin{array}{c}\text { ALL } \\
\mathrm{N}=38\end{array}$ & $\begin{array}{c}\text { OT } \\
\mathrm{N}=9\end{array}$ & $\begin{array}{c}\text { CFT } \\
\mathrm{N}=29\end{array}$ & $p$ \\
\hline Potential skin exposure (mcg) & $255.47(14.61-20$ 654.24) & $6161.50(53.30-20654.24)$ & 158.99 (14.61-7 658.35) & 0.005 \\
\hline Potential skin exposure $\left(\mathrm{mcg} / \mathrm{cm}^{2}\right)$ & $1.20(0.06-103.44)$ & $24.88(0.28-103.44)$ & $0.90(0.06-39.99)$ & 0.006 \\
\hline Gloves exposure (mcg) & $12.78(0.13-1473.94)$ & $17.61(0.13-156.51)$ & $6.50(0.13-1473.94)$ & 0.693 \\
\hline Actual skin exposure (mcg) & $1.62(0.09-8278.86)$ & $3.87(0.09-8$ 278.86) & $1.45(0.10-2364.46)$ & 0.400 \\
\hline Actual skin exposure $\left(\mathrm{mcg} / \mathrm{cm}^{2}\right)$ & $0.009(<0.001-33.429)$ & $0.020(<0.001-33.429)$ & $0.008(<0.001-11.534)$ & 0.503 \\
\hline Hands exposure (mcg) & $139.65(5.85-4$ 724.25) & $232.05(5.85-4$ 724.25) & 77.40 (19.60-4 023.30) & 0.345 \\
\hline Total Potential Exposure (mcg) & $305.04(15.95-20$ 810.75) & $6161.63(53.43-20$ 810.75) & 171.25 (15.95-7 700.91) & 0.008 \\
\hline Total Actual Exposure (mcg) & $147.11(5.94-8421.81)$ & $311.71(5.94-8$ 421.81) & $78.52(19.75-4075.54)$ & 0.187 \\
\hline Pre-exposure ETU (mcg/L) & $0.62(0.12-13.46)$ & $0.83(0.35-13.46)$ & $0.62(0.12-3.84)$ & 0.319 \\
\hline Pre-exposure ETU (mcg) & $0.89(0.25-22.90)$ & $1.04(0.41-22.90)$ & $0.86(0.25-7.25)$ & 0.271 \\
\hline Pre-exposure ETU (mcg/g Creatinine) & $0.70(0.14-12.35)$ & $0.93(0.29-12.35)$ & $0.51(0.14-4.44)$ & 0.159 \\
\hline Post-exposure ETU (mcg/L) & $1.93(0.34-27.36)$ & $1.62(0.64-27.36)$ & $1.94(0.34-11.67)$ & 0.685 \\
\hline Post-exposure ETU (mcg) & $2.68(0.32-29.55)$ & $3.02(0.76-29.55)$ & $2.51(0.32-16.74)$ & 0.417 \\
\hline Post-exposure ETU (mcg/g Creatinine) & $2.09(0.36-26.31)$ & $3.02(0.44-26.31)$ & $2.06(0.36-11.22)$ & 0.337 \\
\hline
\end{tabular}

Table 6. Environmental and biological monitoring results 


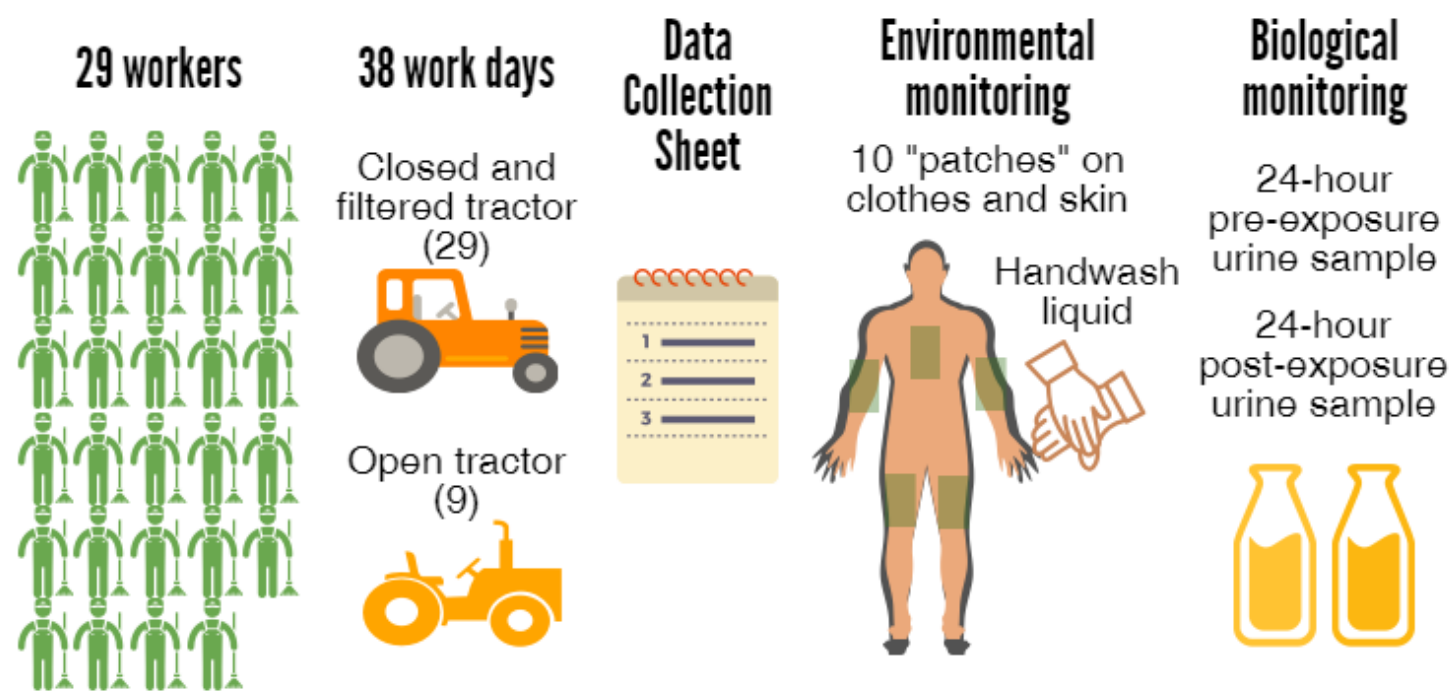

Figure 1. Concept of the study 


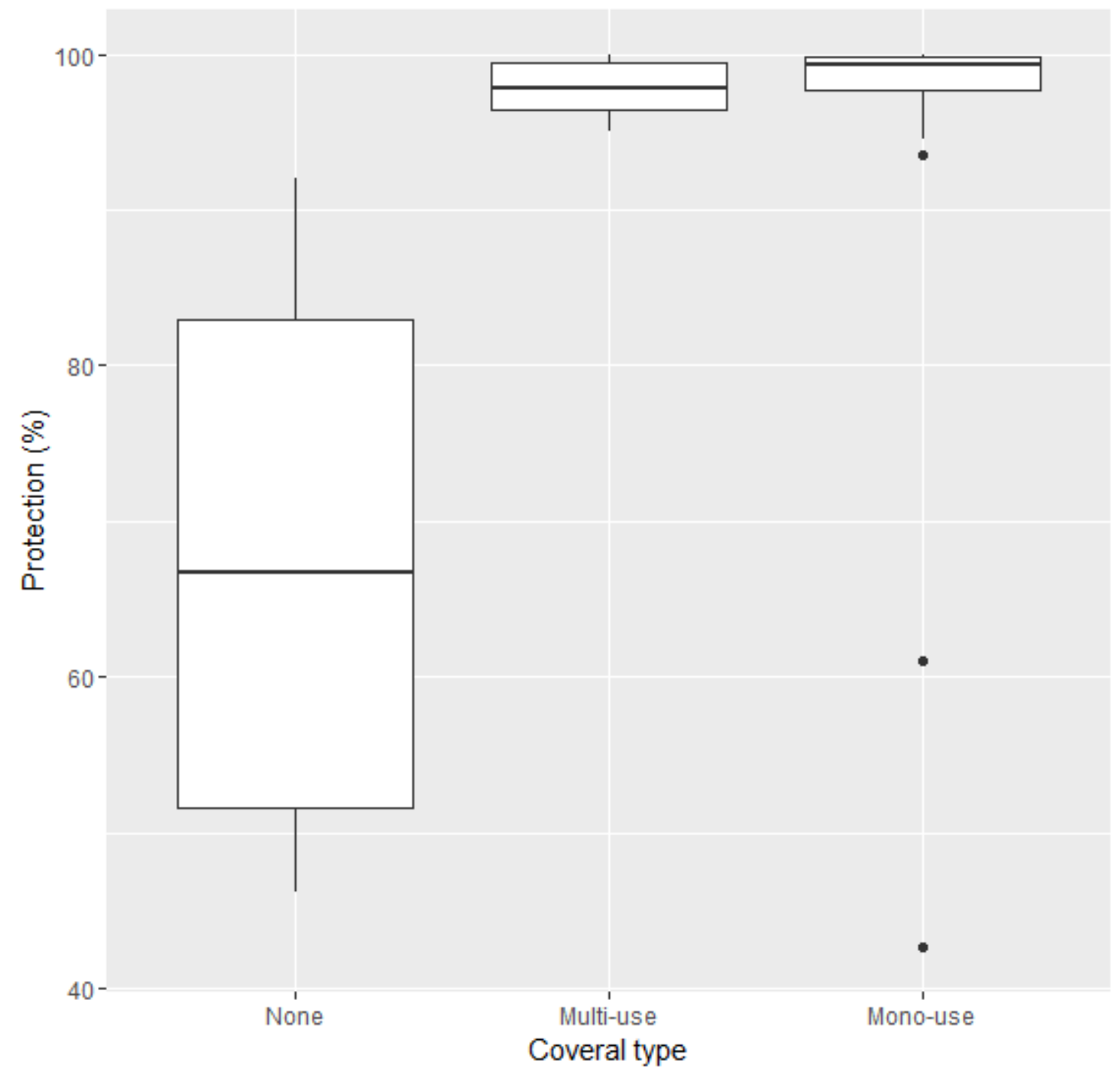

Figure 2. Protection offered by normal clothes (None), multi- and mono-use coverals 


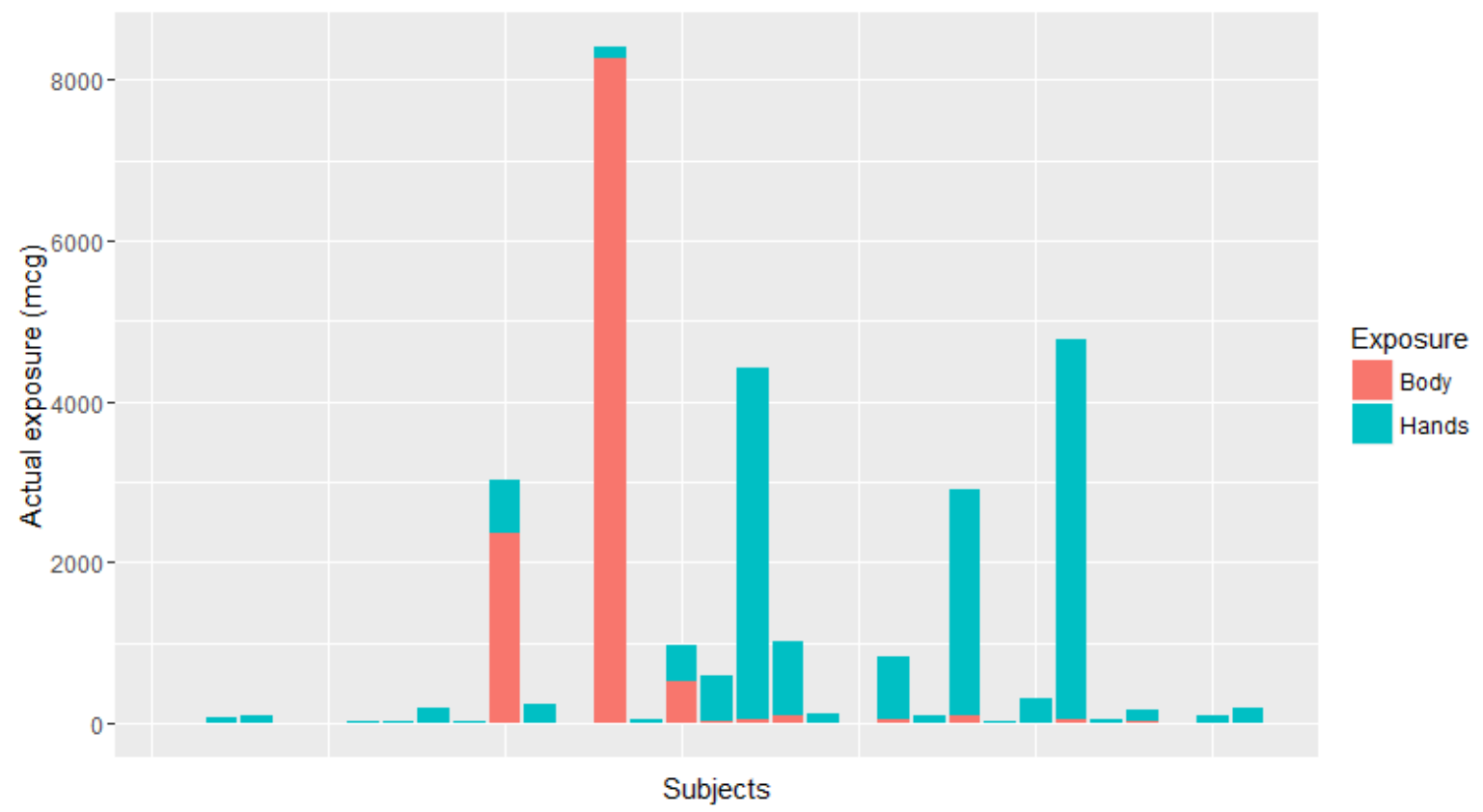

Figure 3. Contribution of hands and body exposure to the total skin exposure in each worker. 
Exposure of hands by glove use and tractor type

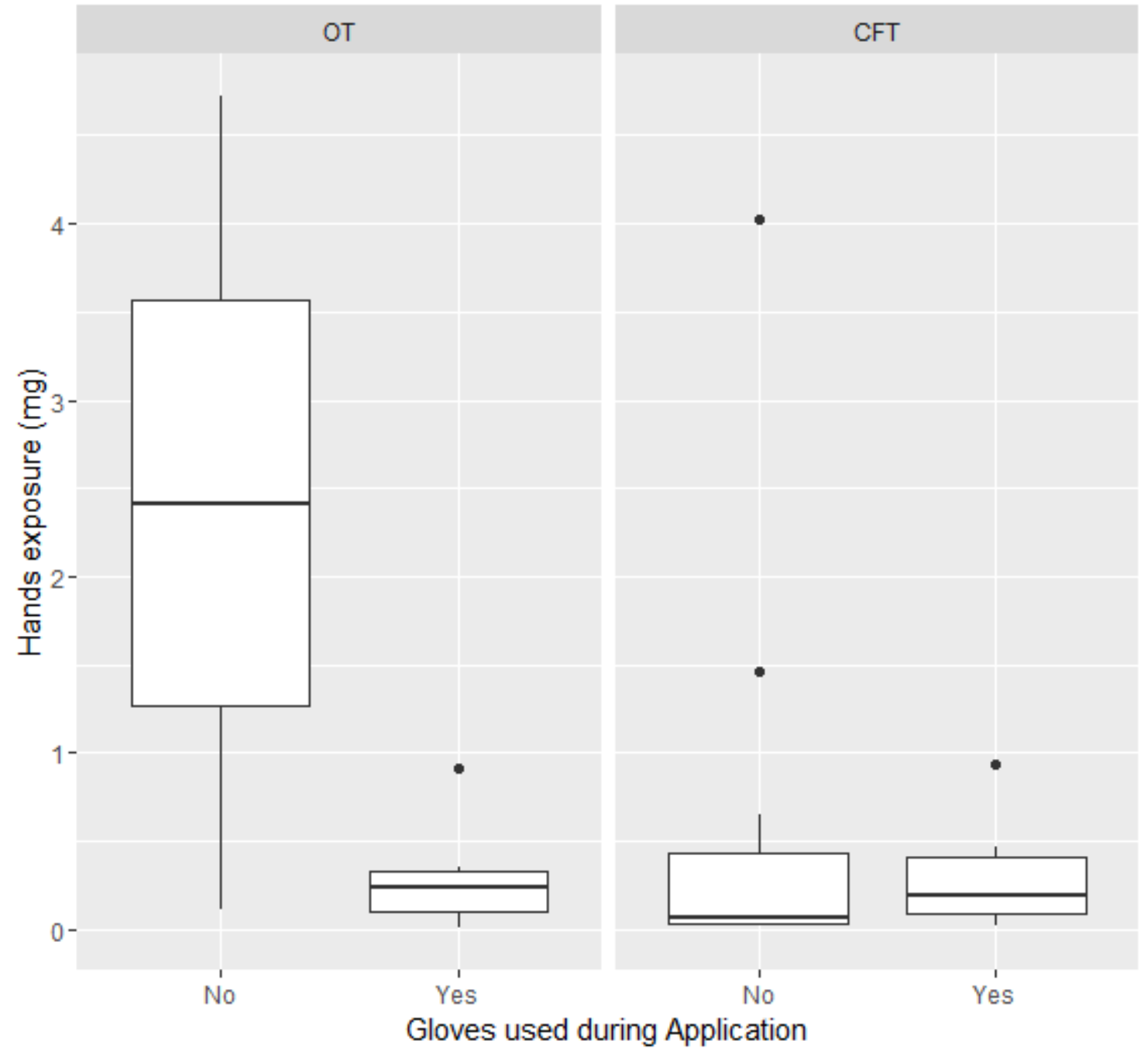

Figure 4. Influence of gloves used during the application phase on hand exposure in OTs and CFTs 


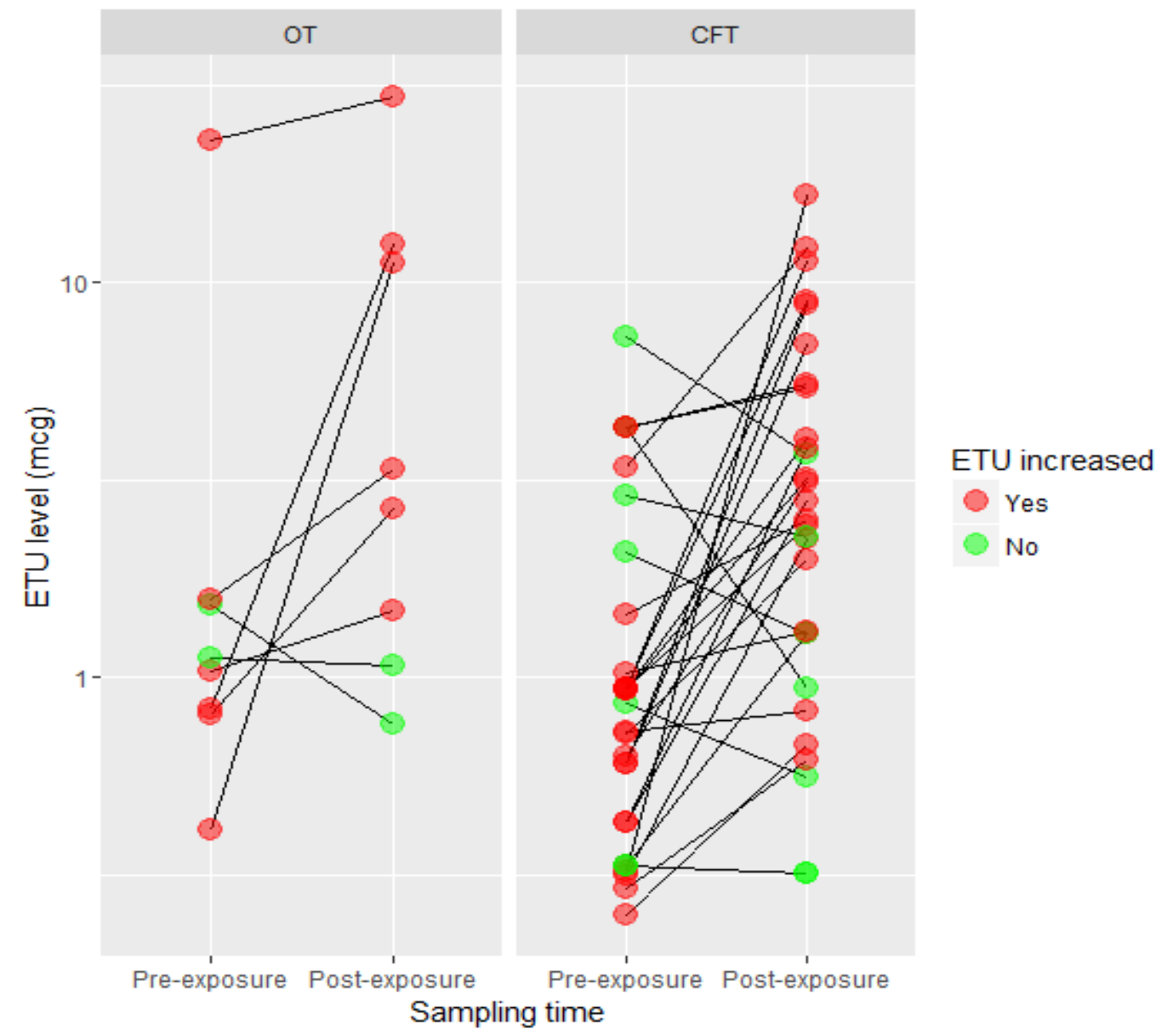

Figure 5. Pre- and post-exposure ETU levels in each worker using OT and CFT 


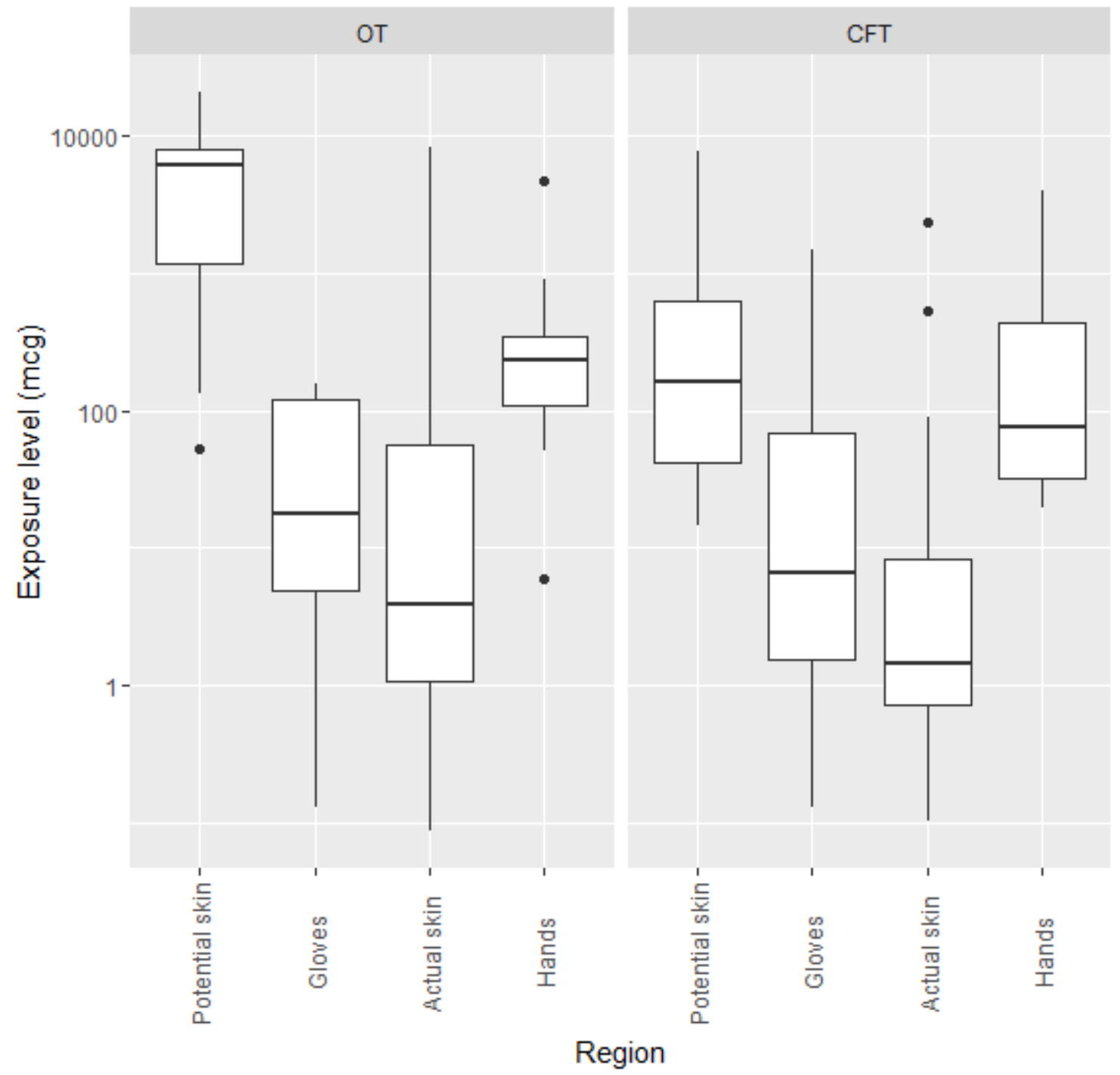

Figure 6. Comparison of potential and actual exposure levels between OT and CFT 